\title{
Sensibilidad de la Salmonella Typhi frente al Cloramfenicol en los últimos 16 años
}

DR. ANTONIO BANF! ***, SRES. OLGA TOISTOY**, PATRICIO MARTINEZ * $*$. MARISOL MON. TOYA ${ }^{* * *}$, ANA NORAMBUENA ***, MIRIAM OCARANZA ***. DIANA PETLRI ***, LEOPOLDO RAZETO t:\$.

El Cloramfenicol continúa siendo la droga más utilizada en el tratamiento de la fiebre tifoidea y su empleo ha dado resultados clínicos exitosos desde hace 25 años (1). Sin embargo, existe la impresión que actualmente ciertos casos de tifoidea tratados con cloramfenicol duran lapsos más largos de lo común en mejorar y esto podría corresponder a la respuesta de cepas de mayor resistencia frente a dicha droga. No es infrecuente ver casos en los cuales la caída de la fiebre viene a ocurrir alrededor del $7^{\circ}-8^{\circ}$ día de tratamiento.

El uso del cloramfenicol que se prolonga por muchos años podría estar determinando la selección de cepas resistentes. El laboratorio de referencia para gérmenes entéricos de Colindale en Inglaterra, recibió 2 cepas de Salmonella typhi aisladas en Chile entre los años 1966-1969 y cuyas CIM (150 y $12,5 \mathrm{ugr} / \mathrm{ml})$ revelaban resistencia al cloramfenicol (2). Esta resistencia no pudo ser transferida a cepas receptoras ni tampoco pudo ser movilizada por un factor de transferencia (episoma).

Estos hechos clínicos y de laboratorio han sido el motivo de determinar la sensibilidad de la salmonella typhi frente al cloramfenicol en los áltimos 16 años.

Material Y METODO. 1.- Se estudiaron 641 cepas de salmonella typhi aisladas entre los años 1958-1974. La gran mayoría de ellas fueron proporcionadas por la sección cepario del Instituto Bacteriológico de Chile. El resto provino de los Hospitales del Salvador, Calvo Mackenna y Roberto del Río. El promedio de cepas estudiadas cada año fue de 42 con cifras mínima y máxima de 16 y 56 respectivamente. Los años 1959 y 1970 no se estudiaron por no haber cepas suficientes.

\footnotetext{
* Hospital Luis Calvo Mackenna. ** Unidad de Microblologia Area Oriente. Universidad de Chile
}

2.- El estudio de la sensibilidad se lizo de acuerdo al método de dilución en placa mediante el equipo de Steers (3) el cual permi ie el estudio simultáneo en cada dilución de droga, de 32 cepas.

Resultados. En la tabla 1 se observa el período $1958-1965$ y es posible apreciar que alrededor del $80 \%$ de las cepas estudiadas tienen una CIM de 3.12 ugr $/ \mathrm{ml}$ y que en los años 1960 y

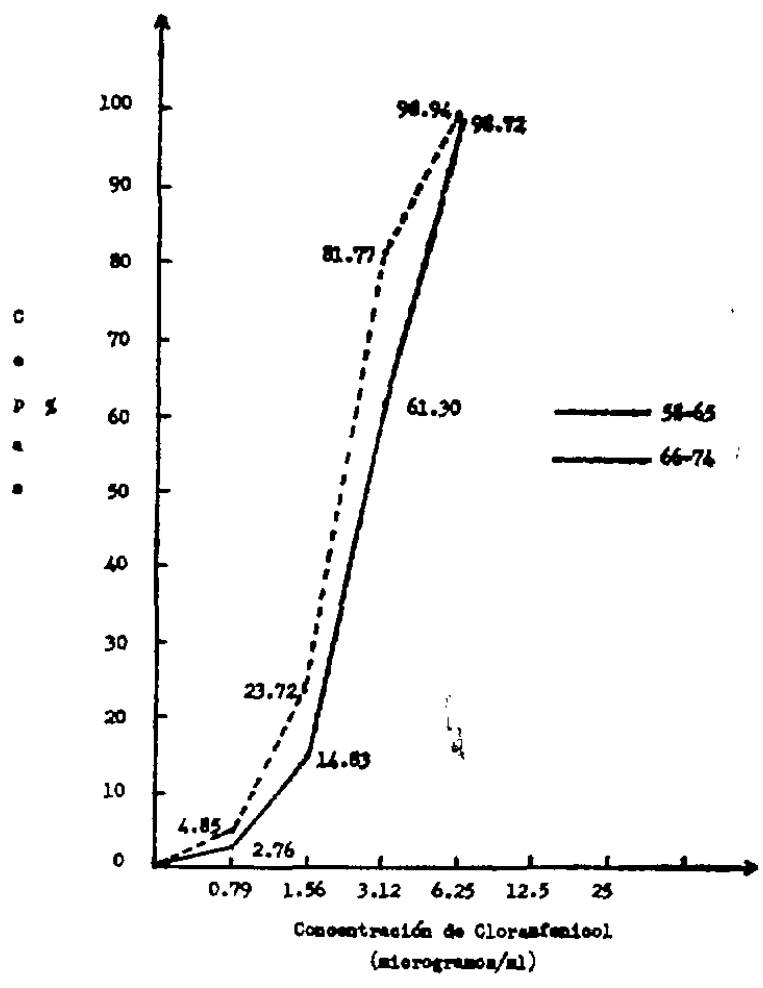

Figura N 1.- Sensibilldad frente a Cloramfenlcol de 641 cepas de $\mathrm{S}$. Typhi. Períodos: $1958-1965$ y $1966-1974$. 
1962 la CIM es de 6,25 ugr $/ \mathrm{ml}$. En la labla 2 se muestra los resultados de las cepas estudiadas entre 1966 y 1974 comprobándose que un $60 \%$ de las cepas tienen una CrM de $3,12 \mathrm{ugr} / \mathrm{ml}$.

En la figura No 1 se comparan los resultados de los 2 períodos señalatos: $1958-1965$ y 1966 . 1974.

En la figura N: 2 se muestra el porcentaje, del total de cepas estudiadas, sensible a cada dilución de cloramfericol.

De estos resultados es posible observar que las concentraciones $12,5 \mathrm{ugr} / \mathrm{ml}$ y más se muestran activas para todas las cepas estudiadas.

En el período 1958-1965, la concentración de $3,12 \mathrm{ugr} / \mathrm{ml}$ presenta gran actividad $(81,77 \%)$. En cambio en el período 1966-1974 el porcentaje de cepas resistentes a $3,12 \mathrm{ugr} / \mathrm{ml}$ es mayor $(40 \%)$.

COMENTARlo. Es posible asumir que la resistencia al cloramfenicol que pueda presentar la salmonella typhi en el futuro, pueda resultar de la mutación genética (4) o de la adquisición de factores R (5). En un país como Chile, en que anualmente ocurren unos 3.000 a 5.000 casos de tifoidea notificados (6) la posibilidad de aparición de cepas resistentes por ambos mecanismos es muy clara; el uso de cloramfenicol debería estar restringido a aquellas infecciones en que es droga de elección y así se disminuiría el riesgo de presentación de factores R. En aquellos casos

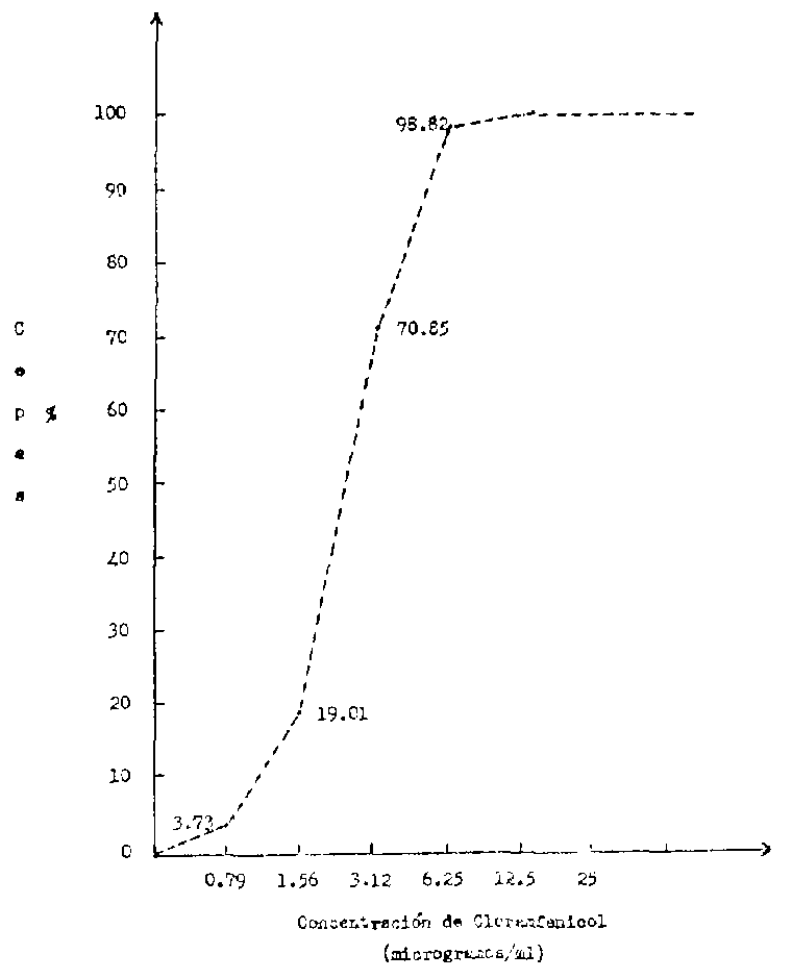

Flgura Nou 2.- Sensibilidad frente al Cloramfenicol de 641 cepas de S. Typhi, $1958-1974$.

T A B L A I

SENSIBILIDAD DE S. TYPHI FRENTE A CLORAMFENICOL 1958-1965

\begin{tabular}{cccccccc}
\hline Concentración & 1958 & 1960 & 1961 & 1962 & 1963 & 1964 & 1965 \\
CAF (ugr/ml) & $\% \mathrm{~S}$ & $\% \mathrm{~S}$ & $\% \mathrm{~S}$ & $\% \mathrm{~S}$ & $\% \mathrm{~S}$ & $\% \mathrm{~S}$ & $\% \mathrm{~S}$ \\
0,79 & 13,63 & 18,52 & 1,85 & 0 & 0 & 0 & 0 \\
1,56 & 31,82 & 24,07 & 41,67 & 1,85 & 66,67 & 0 & 0 \\
3,12 & 100 & 48,15 & 100 & 51,85 & 100 & 84,91 & 87,50 \\
6,25 & 100 & 96,30 & 100 & 96,30 & 100 & 100 & 100 \\
12,5 & 100 & 100 & 100 & 100 & 100 & 100 & 100 \\
\hline
\end{tabular}

T A B L A 2

SENSIBILIDAD DE S. TYPHI FRENTE A CLORAMFENICOL 1966-1974

\begin{tabular}{ccccccccc}
\hline Concentración & 1966 & 1967 & 1968 & 1969 & 1971 & 1972 & 1973 & 1974 \\
CAF (ugr/ml) & $\% \mathrm{~S}$ & $\% \mathrm{~S}$ & $\% \mathrm{~S}$ & $\% \mathrm{~S}$ & $\% \mathrm{~S}$ & $\% \mathrm{~S}$ & $\% \mathrm{~S}$ & $\% \mathrm{~S}$ \\
0,79 & 0 & 0 & 2,08 & 0 & 0 & 0 & 20 & 0 \\
1,56 & 2,0 & 12,96 & 2,08 & 4,55 & 0 & 0 & 62,50 & 34,61 \\
3,12 & 46 & 96,30 & 79,17 & 47,73 & 12,5 & 15 & 93,75 & 100 \\
6,25 & 100 & 98,15 & 91,67 & 100 & 100 & 100 & 100 & 100 \\
12,5 & 100 & 100 & 100 & 100 & 100 & 100 & 100 & 100 \\
\hline
\end{tabular}


de tifoidea, en los cuales se observa una respuesta tardía al empleo del cloramfenicol debe estudiarse la CIM-CBM de la cepa causante del cuadro.

El estudio de la sensibilidad de la salmonella typhi, al igual que otros gérmenes, debe ser preocupación constante con el objeto de utilizar racionalmente los antibióticos; de no hacerlo así se corre el riesgo que en un futuro cercano la salmonella typhi pueda ser resistente al cloramfenicol.

\section{RESUMEN}

Se estudia la sensibilidad de 641 cepas de salmonella typhi, aisladas entre 1958 y 1974, frente al cloramfenicol.

Se demuestra una disminución de la sensibilidad de las cepas en el período 1966-1974 ya que sólo un $60 \%$ de ellas son sensibles a 3,12 ugr $/ \mathrm{ml}$.

Se advierte el peligro del mal uso del cloramfenicol como causante de la selección de cepas de salmonella typhi resistentes a esa droga.

Se señala la necesidad de estudios sistemáticos de la sensibilidad de la salmonella typhi frente al cloramfenicol.

\section{SUMMARY}

-641 strains of salmonella typhi isolated in the period between 1958-1974 were studied for sensibility to cloramphenicol.
-It was observed a reduction in sensibility of salmonella typhi of the years 1966 to 1974 . Only $60 \%$ of them were sensitive to $3.12 \mathrm{ugr} / \mathrm{ml}$.

-The misuse of choramphenicol could be the cause of the selection of resistant strains.

- Systematic studies of MIC (Minimal inhibitory Concentration) of salmonella typhi against cloramphenicol are necessary.

\section{REFERFNCIAS}

1.- Kraljevic, R.; Perroni, J,; Pearson, E.; Sesnic, R.; González, O.; Borel, H.; Rojas, M. y Jiménez, L. Cloromicetina y Tifoidea. Experiencia sobre 500 casos. Rev. Méd. Chil,, 80: 521, 1952.

2.-Rnderson, E. S.; Smith, H. R. Cloramphenicol resistance in the typhoid bacillus. Brit. Med. J. 3: 329-331, Aug. 5, 72.

3.-Steers, E.; Foltz, E. L.; Graves, B. S. Inocula Replicating apparatus for routine testing of bacterial susceptibility. Antibiot. Chemother. (Med. Encyclopedic Inc., New York) 9: 307-311, 1959.

4.-Datta, N. Infectious Drug Resistance. Brit. Med. Bull. 21: 255 (1965).

5.- Watanabe, $T$. Infective heredity of nultiple drug resistance in bacteria. Bact. Rev. 27: 788-794, 1963.

6.-Anuario SNS. Enfermedades de notificación obligatoria, 1970. 